\title{
APLIKASI PENDATAAN SERVIS BARANG BERBASIS CLIENT SERVER PADA TOKO ACCURATE JAYA SANGATTA
}

\author{
Shinta Palupi ${ }^{1)}$, Yulindawati ${ }^{2)}$, Victor Sarangnga ${ }^{3)}$ \\ ${ }^{1,2}$ Teknik Informatika, STMIK Widya Cipta Dharma \\ ${ }^{3}$ Teknik Informatika, STMIK Widya Cipta Dharma \\ 1,2,3 Jl. Prof. M. Yamin No. 25, Samarinda, 75123 \\ E-mail : caca_200177@gmail.com ${ }^{1)}$,yuli.linda08@yahoo.com ${ }^{2)}$, vladimir_cs2@yahoo.com ${ }^{3)}$
}

\begin{abstract}
ABSTRAK
Penelitian yang dilakukan bertujuan untuk membangun sebuah aplikasi pendataan servis barang berbasis client-server, aplikasi tersebut dibuat untuk mempermudah pendataan sekaligus kontrol terhadap barang yang akan diservis dan juga membantu karyawan agar pekerjaan dapat berlangsung lebih efisien dengan meminimalisir segala proses yang masih dilakukan secara manual.

Penelitian ini dilakukan pada Toko Accurate Jaya Computer di Jl. Yos Sudarso , Teluk Llingga Kota Sangatta. Metode pengumpulan data yang digunakan yaitu studi lapangan dan studi pustaka. Untuk metode pengembangan sistem yang digunakan yaitu waterfall. Untuk metode analisis dan desain sistem penulis menggunakan Data Flow Diagram (DFD), Hierarchy Plus Input Output (HIPO), Entity Relationship Diagram (ERD) serta struktur Database input output system. Perangkat lunak yang digunakan adalah Microsoft Visual Basic 6.0 sebagai bahasa pemrograman, Seagate Crystal Report 8 untuk pembuatan laporan, dan Microsoft Access 2007 untuk pembuatan database. Untuk Ujicoba/ Testing Penulis Menggunakan Black Box dan White Box.

Dari hasil penelitian ini diperoleh sebuah aplikasi berbasis Microsoft Visual Basic 6.0 yang berbasis client-Server, yang bertujuan untuk mengatasi berbagai kendala dalam hal-hal yang menyangkut servis barang pada Toko Accurate Jaya, baik dalam hal pendataan barang masuk, pendataan pelanggan, inventarisasi biaya kerusakan, proses persetujuan servis dan konfirmasi kerusakan terhadap konsumen, hingga pembuatan laporan servis barang. Tujuan dari fungsi client-server pada aplikasi itu sendiri dimaksudkan agar data dapat diakses oleh semua karyawan, baik administrator maupun teknisi pada satu perangkat server sehingga tidak perlu dilakukan cross-check atau sinkronisasi data.
\end{abstract}

Kata Kunci: Servis Barang, Pendataan, Client Server

\section{PENDAhUluAN}

Toko Accurate Jaya Computer Sangatta merupakan salah satu toko komputer yang melayani penjualan dan perbaikan alat-alat komputer, baik itu pc komputer maupun laptop serta printer. Pc yang di jual pada toko ini adalah pc dengan harga bersaing, mulai dari harga termurah sampai dengan pc dengan kualiatas dan harga yang relative mahal. Sedangkan untuk laptop yang di jual adalah merk Acer, Toshiba, Axioo, Dell, dan Sony. Untuk perbaikan yang dilayani adalah segala jenis pc, laptop dan printer.

Sistem Pendataan perbaikan barang pada toko komputer accurate jaya sangatta terdapat permasalahan terhadap pemantauan barang-barang yang yang sudah diperbaiki maupun yang belum diperbaiki. Dimana setiap permintaan perbaikan barang hanya didata dalam buku catatan, dan juga untuk mengetahui barang apa saja yang sudah lama masuk dibagian perbaikan memerlukan waktu dan tenaga karena harus di lihat dahulu pada buku catatan.
Berdasarkan masalah tersebut, maka untuk membantu menyelesaikan permasalahan yang dihadapi, dibuat suatu aplikasi pendataan service barang yang berbasis jaringan Client - Server. Aplikasi yang dibuat adalah dalam bentuk Microsoft Visual Basic 6.0 sebagai softwarenya, Microsoft Access 2007 sebagai databasenya dan Seagate Crystal Report 8.0 sebagai Laporannya.

Harapan dari dibuatnya aplikasi ini adalah agar dapat mengatasi kendala-kendala yang ada pada Toko Accurate Jaya Computer Sangatta, baik itu dalam hal permintaan perbaikan barang, barang yang sudah diperbaiki, barang yang belum diperbaiki hingga mengetahui jumlah perbaikan barang perhari. Fungsi jaringan Client - Server itu sendiri adalah untuk mempermudah proses perbaikan barang mulai dari pendataan barang, perbaikan barang, konfirmasi perbaikan barang hingga barang tersebut diserahkan kepada pelanggan. Pendataan barangnya dapat dilakukan oleh semua karyawan dengan membuka aplikasi pada masing-masing komputer karyawan. 


\section{RUANG LINGKUP PENELITIAN}

Dalam penelitian ini permasalahan mencakup:

1. Cakupan permasalaahan.

Cakupan-cakupan permasalahan diantaranya dalam hal permintaan perbaikan barang, barang yang sudah diperbaiki, barang yang belum diperbaiki hingga mengetahui jumlah perbaikan barang perhari. Fungsi jaringan Client - Server itu sendiri adalah untuk mempermudah proses perbaikan barang mulai dari pendataan barang, perbaikan barang, konfirmasi perbaikan barang hingga barang tersebut diserahkan kepada pelanggan. Pendataan barangnya dapat dilakukan oleh semua karyawan dengan membuka aplikasi pada masing-masing komputer karyawan.

2. Batasan-batasan penelitian.

1. Input, tahapan input pada aplikasi pendataaan service barang yaitu:
a. Data Pelanggan
b. Data Karyawan
c. Data Barang.

2. Transaksi, tahapan transaksi pada aplikasi pendataan service barang yaitu:
a. Proses Pendataan Barang yang akan diperbaiki
b. Proses Konfirmasi Barang
c. Proses Perbaikan Barang

3. Output, tahapan output pada aplikasi pendataan service barang yaitu:

a. Laporan Daftar Pelanggan

b. Laporan Daftar Karyawan

c. Laporan Daftar Barang

d. Laporan Data Barang Yang diperbaiki

e. Laporan Barang Yang Sudah Dikonfirmasi

f. Laporan Barang Yang Belum Dikonfirmasi

3. Rencana hasil yang didapatkan.

Aplilasi Pendataan Servis Barang Berbasis Client Server Pada Toko Accurate jaya Computer Sangatta

\section{BAHAN DAN METODE}

\subsection{Penjelasan Bahan}

Menurut Andino (2003), dalam Bahasa Inggris "Application" merupakan software yang dibuat oleh suatu perusahaan untuk mengerjakan tugas-tugas tertentuSedangkan application program adalah program komputer yang dibuat untuk mengerjakan atau menyelesaikan masalah-masalah khusus.

Application programming (pemrograman aplikasi) adalah orang yang menulis program menggunakan komputer sebagai alat memecahkan masalah aplikasi tertentu (Covington dan Downing, 2002).

Menurut Wahid (2001), Application Programming Interface (API) adalah serangkaian fungsi yang dapat digunakan oleh program untuk membuat sistem operasi mengerjakan tugasnya.
Service adalah proses perbaikan terhadap suatu barang yang telah rusak atau tidak bisa digunakan lagi (Kamus Besar Bahasa Indonesia Cetakan Pertama Edisi Ketiga, 2001).

\subsection{Metode}

Pengembangan sistem menggunakan metode Waterfall, metode ini merupakan yang sering digunakan oleh penganalisa sistem pada umumnya, inti dari waterfall adalah pengerjaan dari suatu sistem yang dilakukan secara berurutan atau secara linier.

Jadi jika langkah satu belum dikerjakan maka tidak bias melakukan pengerjaan langkah 2, 3 dan seterusnya. Secara otomatis tahapan ke-3 akan bisa dilakukan jika tahap ke-1 dan ke-2 sudah dilakukan.

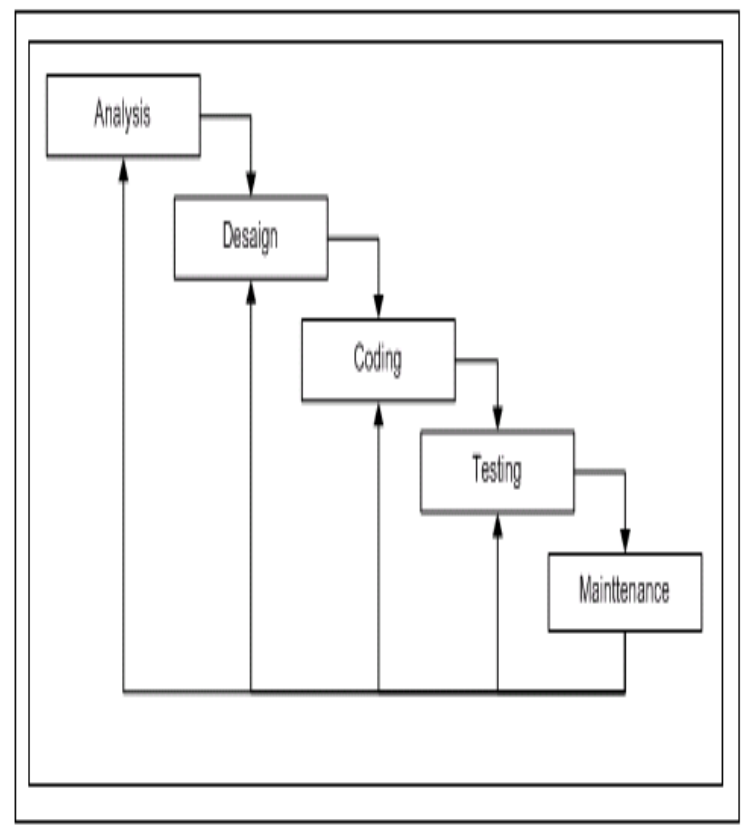

Gambar 1. Model Pengembangan Air Terjun

\section{RANCANGAN SISTEM/APLIKASI}

1. FOD yang berjalan

Dimulai dari entitas pelanggan membawa barang ke entitas admin, kemudian dari entitas admin akan membuat inputan manual barang masuk, kemudian barang diserahkan ke bagian servis. Dari bagian servis akan dilakukan pemerikasaan kerusakan yang dialami oleh barang. Setelah kerusakan ditemukan maka akan dilakukan proses pengerjaan terhadap barang tersebut. Setelah barang diperbaiki, barang akan diserahkan kepada entitas admin. Kemudian entitas admin membuatkan nota pembayaran untuk pelanggan. Kemudian entitas admin akan melakukan proses pembuatan laporan yang akan menghasilkan laporan pelanggan, laporan barang service dan laporan pendapatan service yang akan diserahkan kepada entitas pimpinan. 


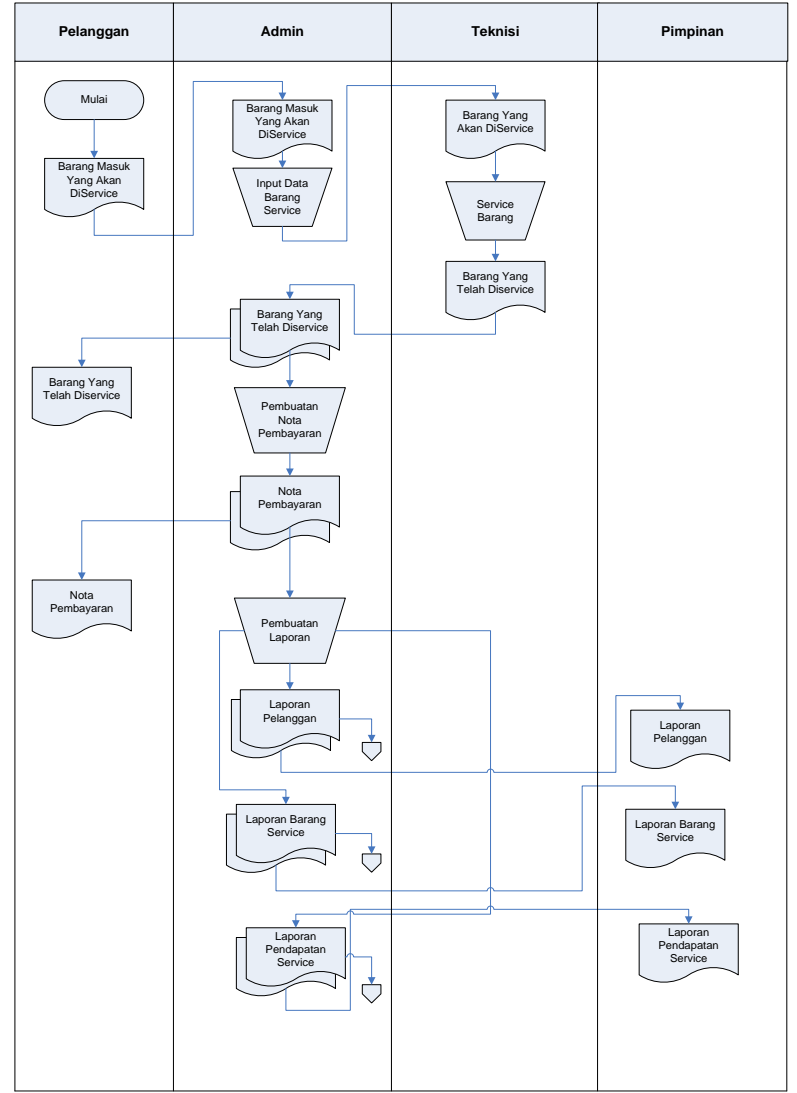

Gambar 2. FOD Yang Berjalan

\section{FOD yang diusulkan}

dimulai dari entitas pelanggan membawa barang masuk ke entitas admin, kemudian dari entitas admin akan membuat inputan secara terkomputerisasi barang masuk, kemudian barang diserahkan ke bagian service. Dari bagian service akan memeriksa kerusakan yang dialami oleh barang. Setelah kerusakan ditemukan dan ada persetujuan dari pelanggan untuk perbaikannya, maka kan dilakukan pengerjaan service terhadap barang tersebut, namun apa bila belum ada persetujuan, maka bagian servis akan menginputkan informasi kerusakan dan selanjutnya berdasarkan dari data tersebut, entitas admin memberikan konfirmasi kepada pelanggan untuk proses persetujuan servis, apa bila tidak disetujui dan ingin membatalkan perbaikan barang, maka entitas admin akan melakukan proses pembatalan dengan melakukan update terhadap status barang pada tabel konfirmasi .Barang yang batal diservis maupun yang telah diselesaikan akan diserahkan kepada entitas admin. Kemudian entitas admin membuatkan nota pembayaran untuk barang pelanggan yang telah diservis setelah pelanggan memperlihatkan nota serah terima barang yang dibuat sebelumnya. Kemudian entitas admin akan melakukan proses pembuatan laporan yang akan menghasilkan laporan pelanggan, laporan barang masuk dan laporan pendapatan service yang akan diserahkan kepada entitas pimpinan.

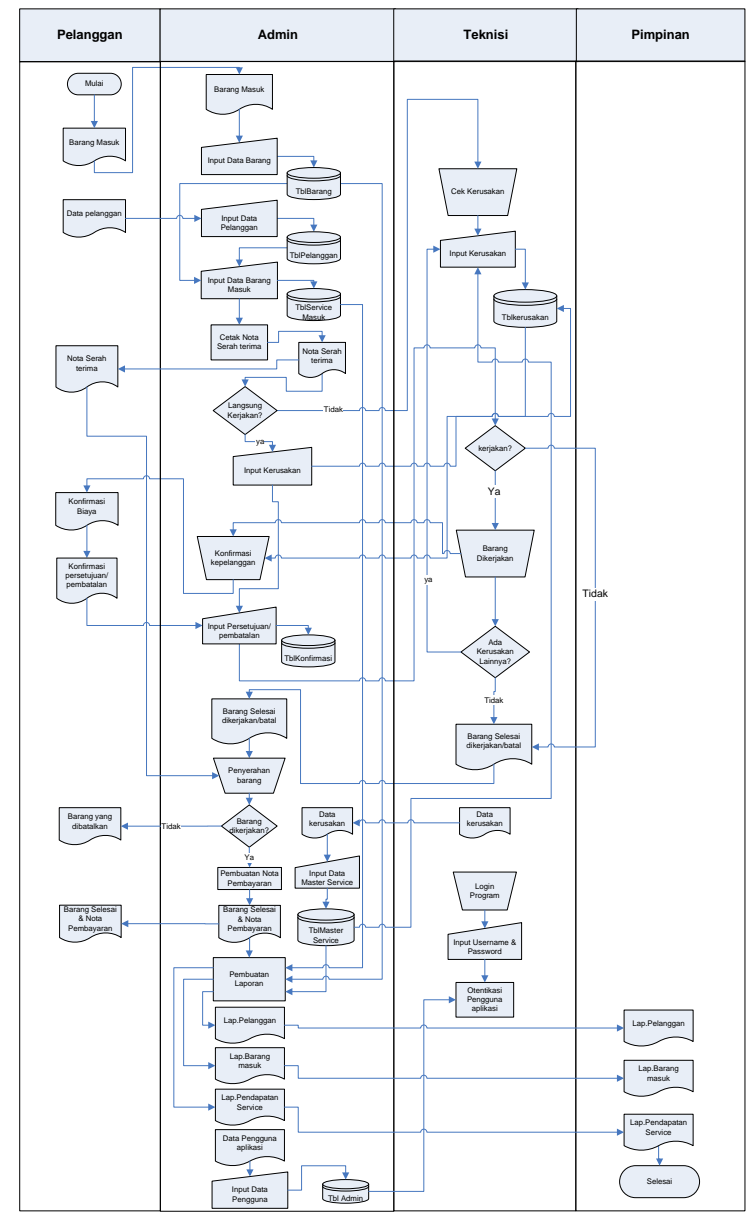

Gambar 3. FOD Yang Diusulkan

\section{Context Diagram}

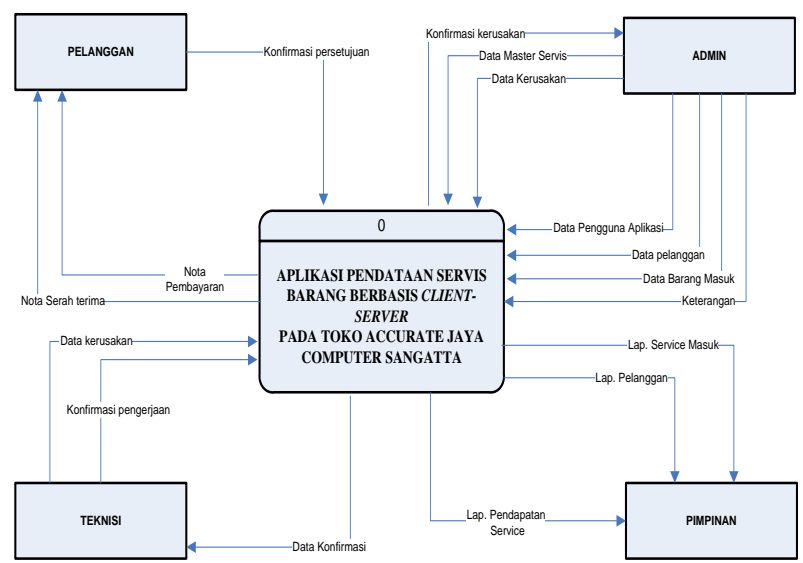

Gambar 4. Context Diagram

gambar diatas merupakan tambilan dari context diagram dimana entitas pelanggan mengirimkan data pelanggan dan data barang ke sistem, serta mendapatkan barang yang telah diservice. Entitas admin mengirimkan data barang masuk ke sistem. Entitas teknisi mengirimkan data barang yang sudah diservice kesistem. Sistem akan menghasilkan laporan barang, laporan pelanggan, laporan master service, laporan barang masuk, dan laporan konfirmasi kepada entitas pimpinan. 
4. Data Flow Diagram (DFD) Level 0

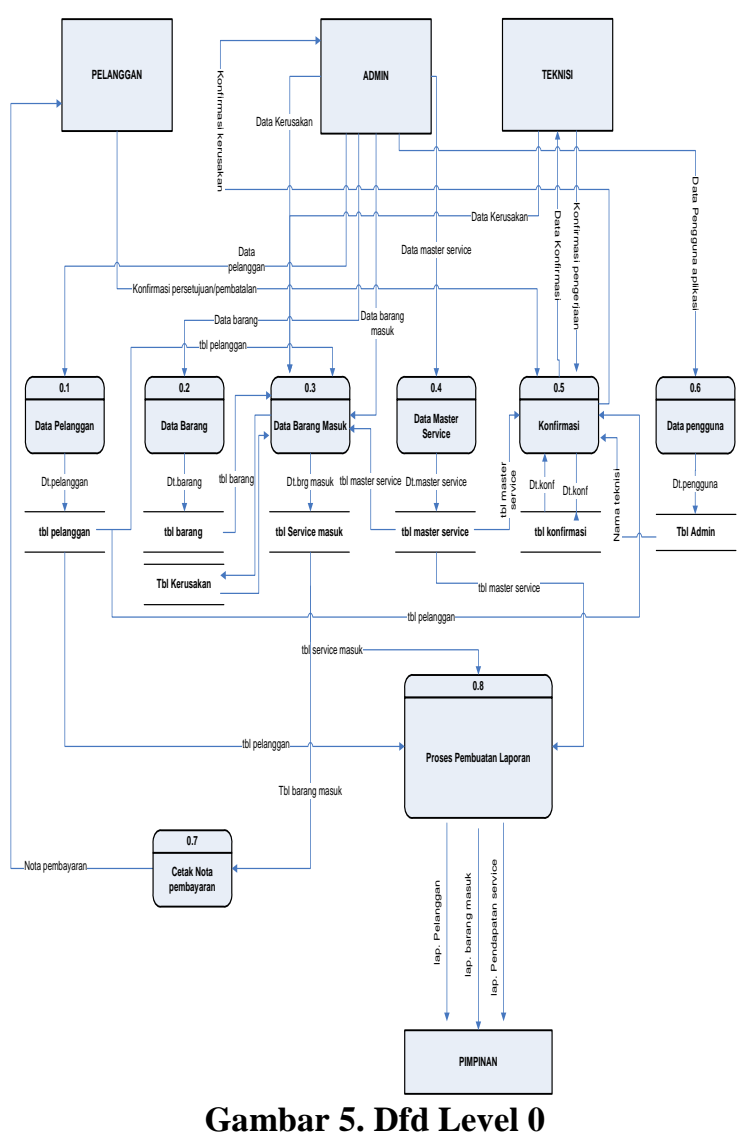

Gambar 5. Dfd Level 0

Data Flow Diagram (DFD) Level 0 dimana entitas pelanggan mengirimkan data pelanggan untuk diproses dan akan disimpan kedalam tabel pelanggan. entitas pelanggan mengirimkan data barang masuk untuk diproses dan akan disimpan kedalam tabel barang masuk. entitas pelanggan mengirimkan data konfirmasi untuk diproses dan akan disimpan kedalam tabel konfirmasi. entitas admin mengirimkan data barang untuk diproses dan akan disimpan kedalam tabel barang. entitas admin mengirimkan data barang masuk untuk diproses dan akan disimpan kedalam tabel barang masuk. entitas admin mengirimkan data master service untuk diproses dan akan disimpan kedalam tabel master service. entitas teknisi mengirimkan data konfirmasi untuk diproses dan akan disimpan kedalam tabel konfirmasi. Table pelanggan digunakan untuk proses barang masuk dan proses konfirmasi. Table barang digunakan untuk proses barang masuk. Table master service digunakan untuk proses barang masuk dan proses konfirmasi. Keseluruhan table yang meliputi table barang, table pelanggan, table master service, table barang masuk dan table konfirmasi digunakan untuk proses pembuatan laporan kepada pimpinan. Sistem akan menghasilkan laporan barang, laporan pelanggan, laporan master service, laporan barang masuk, dan laporan konfirmasi kepada entitas pimpinan.

2. Input data barang

\section{Data Flow Diagram (DFD) Level 1}

Data Flow Diagram (DFD) Level 1 yang terdiri dari table pelanggan yang akan digunakan untuk proses laporan pelanggan dan proses barang masuk yang akan menghasilkan laporan pelanggan dan laporan barang masuk.. Tabel Barang masuk dan Tabel Master Servis digunakan untuk proses laporan barang masuk dan proses laporan pendapatan servis yang akan menghasilkan laporan barang masuk dan laporan pendapatan servis.

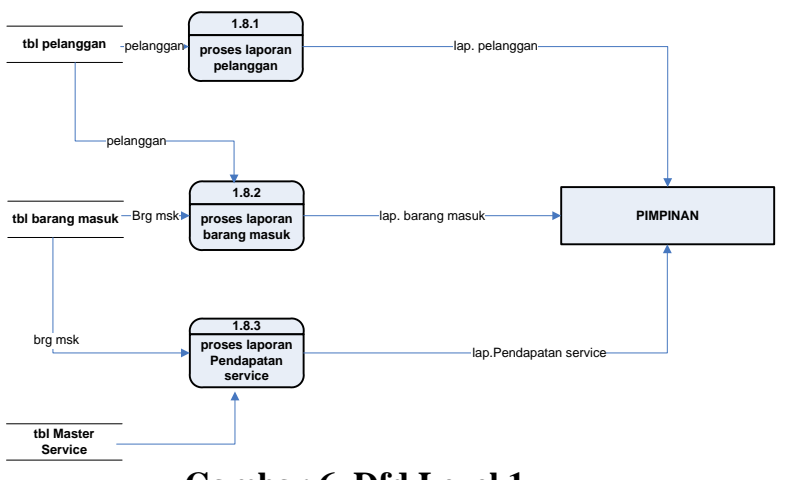

Gambar 6. Dfd Level 1

\section{IMPLEMENTASI}

1. Topologi Dan Arsitektur Jaringan

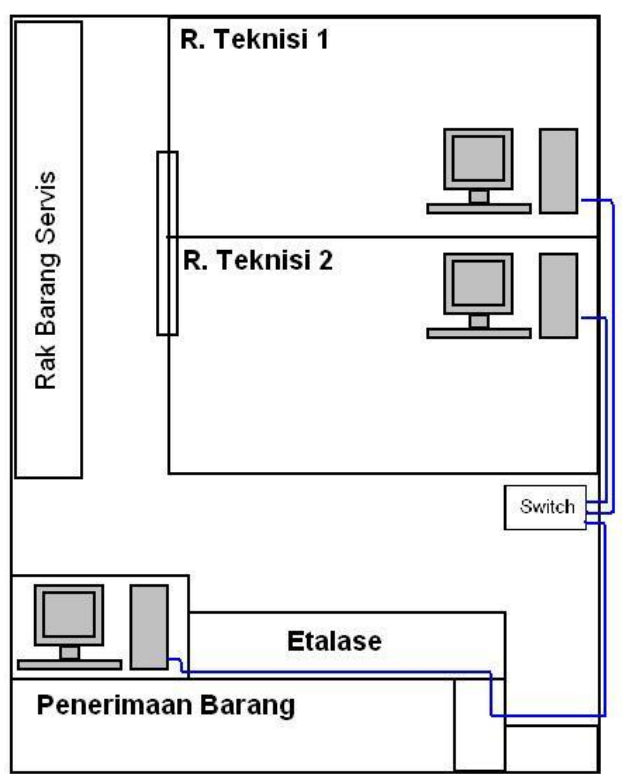

Gambar 7. Arsitektur Jaringan

Gambar diatas merupakan tampilan dari tata letak jaringan yang akan digunakan pada Accurate Jaya Computer Sangatta yang terdiri dari bagian admin (Penerimaan Barang) dan bagian teknisi. 


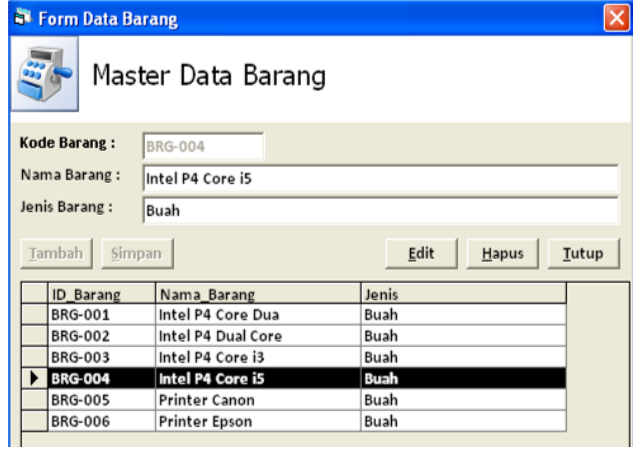

Gambar 8. Form Input data barang

Berdasarkan gambar 8, form input data barang yang terdiri dari kode barang, nama barang dan jenis barang. Tombol tambah berfungsi untuk menambah barang baru. Tombol simpan berfungsi menyimpan barang baru. Tombol edit berfungsi untuk mengubah data yang telah ada. Tombol hapus berfungsi untuk menghapus data yang ada. Tombol keluar berfungsi untuk keluar dari form.

3. Input data Pelanggan

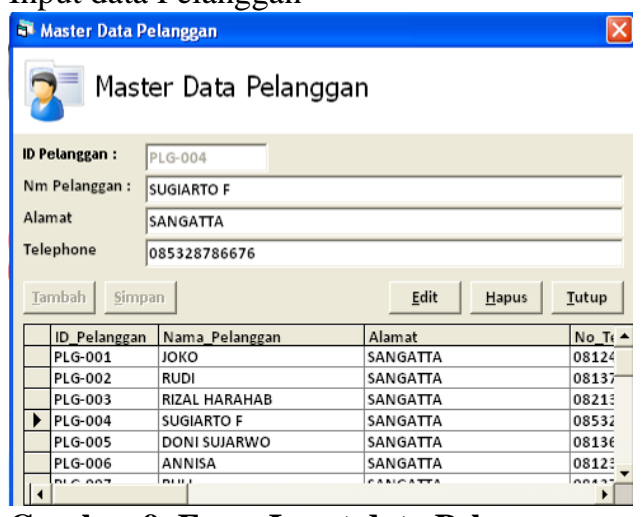

Gambar 9. Form Input data Pelanggan

Berdasarkan gambar 9, data-data pada form input pelanggan terdiri dari id pelanggan, nama pelanggan, alamat dan no telephone. Tombol tambah berfungsi untuk menambah pelanggan baru. Tombol simpan berfungsi menyimpan pelanggan baru. Tombol edit berfungsi untuk mengubah data yang telah ada. Tombol hapus berfungsi untuk menghapus data yang ada. Tombol keluar berfungsi untuk keluar dari form.

4. Input Data Master Service

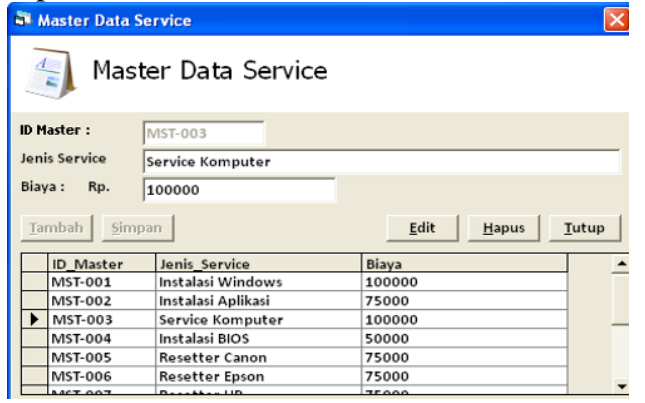

Gambar 10. Form Input Data Master Service
Berdasarkan gambar 10, data-data pada form input master service terdiri dari id master, jenis service dan biaya service. Tombol tambah berfungsi untuk menambah master service baru. Tombol simpan berfungsi menyimpan master service baru. Tombol edit berfungsi untuk mengubah data yang telah ada. Tombol hapus berfungsi untuk menghapus data yang ada. Tombol keluar berfungsi untuk keluar dari form.

5. Input Data Servis Masuk

\begin{tabular}{|c|c|c|c|c|c|c|c|}
\hline \multicolumn{7}{|c|}{ Data Barang Masuk } & $x$ \\
\hline \multicolumn{2}{|c|}{$\stackrel{\infty}{\infty}$} & \multicolumn{5}{|c|}{ Data Barang Masuk } & \\
\hline \multirow{4}{*}{\multicolumn{2}{|c|}{$\begin{array}{l}\text { ID Masuk : } \\
\text { ID Pelanggan : } \\
\text { ID Barang : } \\
\text { Kerusakan : }\end{array}$}} & $\begin{array}{l}\text { MSK-002 } \\
\end{array}$ & Tanggal: & $1 \mathrm{~s}$ & 05/2012 & $\nabla$ & \\
\hline & & PLG-006 & 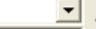 & ANNISA & & & \\
\hline & & BRG-004 & - & Intel PA & Core is & & \\
\hline & & PARAH & & & & & \\
\hline \multicolumn{2}{|c|}{ Tambah } & pan & Cetak For & rmulir & $\underline{\underline{E} \text { dit }}$ & Hapus & Iutup \\
\hline & \multirow{2}{*}{\begin{tabular}{|l|} 
ID_Masuk \\
MSK-001
\end{tabular}} & Tanggal & & & elanggan & ID_Barang & Keru \\
\hline & & $4 / 12 / 2012$ & & & 001 & BRG-001 & Print \\
\hline 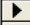 & \multirow{2}{*}{\begin{tabular}{|l|} 
MSK-002 \\
MSK-003
\end{tabular}} & $5 / 19 / 2012$ & & & 006 & BRG-004 & PARA \\
\hline & & $5 / 19 / 2012$ & & & 006 & BRG-006 & ROBE \\
\hline \multicolumn{2}{|r|}{ MSK-004 } & $5 / 21 / 2012$ & & & .004 & BRG-002 & Tidak B \\
\hline
\end{tabular}

Gambar 11. Form Input Data Servis Masuk

Pada gambar 11, data-data pada form input master service terdiri dari id masuk, id pelanggan, id barang dan kerusakan. Tombol tambah berfungsi untuk menambah service masuk baru. Tombol simpan berfungsi menyimpan service masuk baru. Tombol edit berfungsi untuk mengubah data yang telah ada. Tombol hapus berfungsi untuk menghapus data yang ada. Tombol Cetak formulir berfungsi untuk mencetak nota serah terima barang yang akan di service. Tombol keluar berfungsi untuk keluar dari form.

6. Transaksi Kerusakan Barang

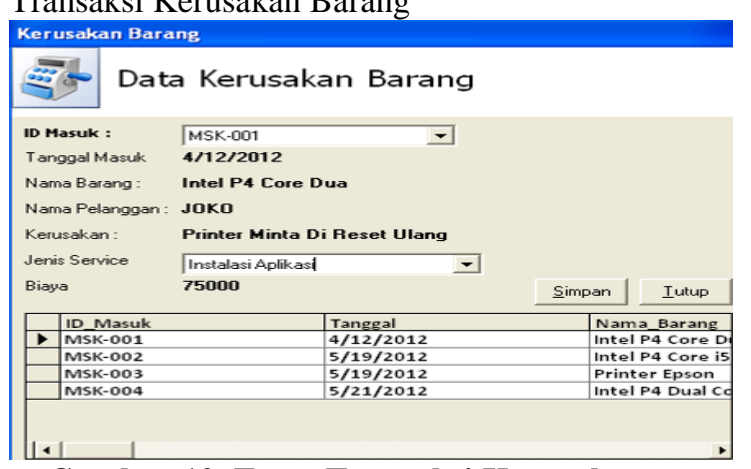

\section{Gambar 12. Form Transaksi Kerusakan} Barang

Pada gambar 12, merupakan tampilan transaksi kerusakan barang dimana terdiri dari id masuk, tanggal masuk, nama barang, nama pelanggan, kerusakan, jenis service dan biaya. Tombol simpan berfungsi untuk menyimpan data kerusakan barang. Tombol tutup berfungsi untuk menutup form dan kembali pada menu utama. 
7. Transaksi Update Status Servis

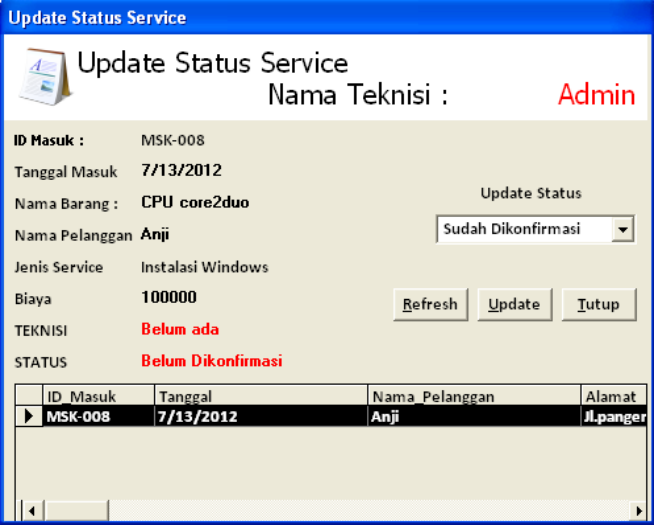

Gambar 13. Form Transaksi Update Status Service

Pada gambar 13, merupakan tampilan transaksi kerusakan barang dimana terdiri dari id masuk, tanggal masuk, nama barang, nama pelanggan, kerusakan, jenis service dan biaya dan status servicenya. Tombol simpan berfungsi untuk menyimpan data kerusakan barang. Tombol tutup berfungsi untuk menutup form dan kembali pada menu utama.

8. Form Laporan Service masuk

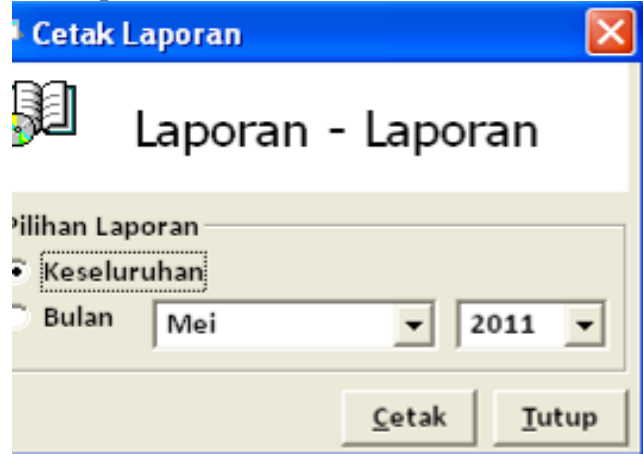

Gambar 14. Form Laporan Service Masuk

Pada gambar 14, merupakan tampilan dari laporan service masuk yang terdiri dari dua pilihan laporan yaitu keseluruhan dan perbulan. Jika tombol cetak di klik maka akan mencetak data service masuk sesuai dengan pilihan yang ditentukan baik itu laporan service masuk secara keseluruhan maupun laporan service masuk secara perbulan da pertahun. Tombol tutup berfungsi untuk menutup form.

\section{KESIMPULAN}

Berdasarkan hasil dari pembahasan dan penjelasan pada bab-bab sebelumnya, maka dapat dibuat kesimpulan yaitu :

1. Aplikasi Servis Barang pada Accurate Jaya Computer Sangatta merupakan suatu sistem yang dibuat untuk mempermudah dalam hal pendataan barang-barang yang akan diservis sehingga memudahkan mengetahui barang apa saja yang akan diservis dan servis barang mana yang disetujui serta mempermudah dalam hal laporan bulanan baik itu laporan servis barang masuk maupun pendapatan servis.

2. Aplikasi Servis Barang pada Accurate Jaya Computer Sangatta ini mempunyai kelemahan yang terletak pada akses data ke server oleh client. Dimana jika komputer server mati atau kabel jaringan tidak dapat terhubung ke server maka semua client baik itu admin hingga pada bagian teknisi tidak akan dapat mengakses program secara langsung dikarenakan hal tersebut. Terlebih jika komputer server rusak sehingga tidak dapat menghubungkan data ke client.

3. Aplikasi pendataan sangat membantu terutama pada badan usaha yang memiliki keterbatasan SDA.

\section{SARAN}

Berdasarkan dari kesimpulan-kesimpulan yang telah dikemukakan diatas, dan juga uraian dan pembahasan pada bab-bab sebelumnya, maka penulis memberikan saran-saran sebagai berikut :

1. Penggunaan database via jaringan masih mengandalkan metode drive mapping dan data belum dienkripsi, untuk keamanan data, akan lebih baik bila diterapkan enkripsi terhadap database.

2. Untuk pengembangan sistem berikutnya diharapkan program bisa dikembangkan dengan sistem aplikasi servis barang berbasis online sehingga pendataan dapat dilakukan secara langsung.

3. Aplikasi servis barang ini dapat dikembangkan untuk bidang lainnya dan tidak terbatas pada servis komputer semata.

4. Sebaiknya menambahkan notifikasi real-time pada proses konfirmasi agar dapat di update segera setelah konfirmasi dari pelanggan dilakukan.

\section{DAFTAR PUSTAKA}

Amsyah, 2001, Data dan Informasi, Penerbit Andi Offshet, Yogyakarta

Andino Maseleno, 2003, Kamus Istilah Komputer dan Informatika, Edisi Ketiga, Penerbit Gaya Media, Jakarta.

Anonim, 2001, Kamus Besar Bahasa Indonesia, edisi ketiga Departemen Pendidikan dan kebudayaan dan balai pustaka, Jakarta.

Bannock, Graham et al, 2003, Dictionary of Economics, Penguin Books.

Covington dan Downing, 2002, Application programming, Penerbit Bina Nusantara, Jakarta

Wahid, 2001, Application Programming Interface (API), Penerbit Gaya Media, Jakarta 